\title{
A presença de arquétipos nos youtubers: modos e estratégias de influência
}

\author{
Pedro Rodrigues Costa' \\ http://orcid.org/0000-0002-1223-6462
}

I - Univesiteit Antwerpen

Universidade do Minho, Braga, Portugal

Resumo: Entre as mudanças ocorridas nos modos de influência, constam os novos formatos possibilitados pelas redes digitais. OYouTube, por meio das "suas" celebridades, é uma dessas redes. As suas formas de influência mesclam esquemas antigos com sistemas sociotécnicos novos. Para perceber essas dinâmicas de influência, selecionamos três youtubers. De modo qualitativo, e a partir da teoria dos arquétipos, estudamos a presença de arquétipos nas estratégias de influência e o modo como estes são utilizados nos títulos, na construção, na legitimação e na manipulação de conteúdos. A criação de figuras e elementos comuns (brincadeira, raiva, violência, vingança, sombra, mãe ou Deus) entre produtor e consumidor é uma das estratégias mais comuns para "capturar" a atenção dos seguidores.

Palavras-chave: youtubers; arquétipos; influência, YouTube.

Abstract: The presence of arquetypes in youtubers: modes and strategies of influence - Among the changes occurred in the modes of influence, there are the new formats made possible by digital networks. YouTube, through "your" celebrities, is one of those networks. Its forms of influence mix old schemes with new socio-technical systems. Based on the SocialBlade rankings, three of the main youtubers in the "Portuguese speaking space" were selected. Qualitatively, and based on the theory of archetypes, the presence of archetypes and the way they are used in titles, construction, legitimation and content manipulation were analyzed. The creation of common figures and elements (play, anger, violence, revenge, shadow, mother or God) between producer and consumer is one of the most common strategies to "capture" the attention of followers.

Keywords: youtubers; archetypes; influence; YouTube.

\section{Introdução}

Para Aristóteles (2002, p. 5), "todo o humano deseja, sobretudo, conhecer". Na ação ou no repouso, "preferimos a vista, por assim dizer, ao resto dos sentidos". Ora, o ecrã, esse 
instrumento da "vista", é um dos objetos prediletos da contemporaneidade, permitindo ainda explorar, consumir e transformar. Com ele, vive-se no reino da imagem (VIRILIO, 2001).

Para Tarde (1978), a "vista" conduz à imitação, à oposição e à adaptação, processos "intermentais" e "intersubjetivos". Quando, em 2006, a Google adquiriu o YouTube, vislumbrou negócio ao perceber esses efeitos, sobretudo se promovesse colisões entre aquele que procura "palco" e aquele que quer "ver". Essas possibilidades sociotécnicas tornaram-se grandes dinâmicas sociais de influência.

O YouTube permitiu novas formas de "associação" (LATOUR, 2012). O youtuber é uma das suas "formas", implicando uma rede entre diversos elementos e formas (discursos, instituições, técnicas, organizações, enunciados, morais). Nele, cruza-se toda uma rede (FOUCAULT, 2000, p. 244).

Os youtubers formam um sistema próprio de celebridades. Seguidos, suscitam gostos e paixões, sugerem tendências e ampliam a ideia de novidade e movimento. Tornaramse grandes referências da cultura "You", essa "unidade" que chega às "tribos" de modo rápido, fácil e simples (BURGESS; GREEN, 2009).

Para Felinto (2008, p. 40), o YouTube não possui "valor de transformação": a quantidade não significa qualidade e a partilha pode não conter contributo cultural. Já Burgess e Green (2009) apontam eixos comuns nos seus vídeos: contêm função referencial sobre determinado contexto; são centrados no "Eu"; e contêm dinâmicas metalinguísticas, devido às suas funções. Destarte, o modo como os vídeos organizam potências dinâmicas de storytelling. As suas técnicas são utilizadas e mescladas com outras: misturam-se estratégias e arquétipos. Os resultados são explosivos, já que grandes volumes de vídeos são consumidos por jovens seguidores (LAMBERT, 2006).

O estudo qualitativo que aqui apresentamos revela essa dinâmica entre youtubers, storytelling e arquétipos. Daqui nascem narrativas e estratégias para capturar a atenção dos seus seguidores, influenciando-os por serem heróis do ecrã no número, no algoritmo, na finança e, também, no pensar, sentir e agir contemporâneo.

\section{Arquétipos e influência digital: estado da arte}

Para Carl Jung (1979, p. 11-13), as crenças, os desejos, o poder e a aprovação social são influenciados por arquétipos que estão nas coletividades, consciente e inconscientemente. A "psique coletiva" é constituída por um fundo de imagens com carácter histórico. Como imagens e representações simbólicas, os arquétipos são restituídos à vida por intermédio de estímulos, exteriores e interiores (ibidem, p. 13).

O romano era cercado por escravos. O escravo e a sua psicologia inundaram a Itália antiga, e todo romano se tornou interiormente-e, claro, inconscientemente - um escravo. Vivendo constantemente na atmosfera dos escravos, ele se contaminou de sua psicologia. (JUNG apud MCLUHAN, 2007, p. 37) 
A metáfora do "romano" e dos "escravos" serve ao YouTube. Imagens circulantes funcionam como expositores de arquétipos, contaminando com associações "intermentais", "intersubjetivas". Ao colocar no título dos vídeos certas palavras, e porque o algoritmo obedece a uma busca numérico-semântica, o youtuber convoca personagens arquetípicas concebendo associações. Podem tornar-se "estereótipos" ou "representações sociais", dependendo do modo de sugestão feito entre produtor, produção e arquétipo (PALACCE, 2011).

Para Tarde (1992, p. 43), o público é uma "coletividade puramente espiritual, como uma dispersão de indivíduos fisicamente separados e entre os quais existe uma coesão somente mental". No YouTube, o voyeur, subscritor ou visualizador estabelece uma relação visual com o youtuber, que depois se estende a uma relação "intermental", "intersubjetiva", com o líder (relação vertical) e com a comunidade de seguidores (relação horizontal). Glosando Tarde (1992), o poder de propagação do youtuber, tendo como "actante" ${ }^{1}$ o dispositivo, supera o da multidão não tanto em intensidade mas em continuidade e constância. Afastado espacialmente, o youtuber tem a vantagem da telemática do smartphone ou do computador, em tempo real, "avisando" os subscritores da sua comunicação ou apelando ao algoritmo numérico de sugestões. Isto permite estratégia, eficácia e alcance (SERRANO, 2008).

De fato, os youtubers só são possíveis na atual contingência. Todo o novo dispositivo permite novos modos de comunicação que movimentam "discursos" e "imagens circulantes", formando intelectos contingentes próprios (FOUCAULT, 2000).

Sendo este o resultado de possibilidades contingentes, ser "líder de opinião" e promover "influência pessoal" fazem parte de uma velha "epistemologia da comunicação", como proposto por Lazarsfeld, Berelson e Gaudet, em 1948. Mas, se no passado se combinava psicologia e sociologia e comunicação, com o YouTube há toda uma nova individuação. Daí a importância do conceito de "influenciador digital" (MARTINO, 2018).

A cinética do influenciador digital não é necessariamente a de youtuber. Este é líder de opinião em diversos domínios do digital. O conceito de "influenciador digital" ajusta-se porque identifica os que "fazem parte de um nicho específico no digital e, dentro deste grupo, possuem um volume de conexões superior à média das pessoas que pertencem a esse nicho" (MESSA, 2016, n.p.). Por isso existem diferenças entre "influenciador digital" e "influenciador de marketing". O segundo é parte específica do primeiro, pois está investido por uma marca ou empresa que se foca em produtos e vendas. Já o primeiro é mais lato na busca de gratificações, procurando também as sociais, as opinativas e as de influência subjetiva (MENEZES, 2014).

Assim, o youtuber como "influenciador" representa o triunfo do individualismo e da cultura "You", sobretudo a partir da Web 2.0 ("prosumidor", expressão de Toffler, 1999). Essa cultura do "You" beneficia-se com a evolução dos "actantes" técnicos que permitem

1 OYouTube inscreve-se na categoria de "objeto", de Latour (2012). É um "actante" que contribui para o movimento e para a rede de ligações, promovendo "traduções" e dobras. 
ao utilizador ser programador. Os prosumidores em geral, e os youtubers em particular, não sendo marionetas nas mãos da finança, estão ao serviço de um "neoliberalismo incessantemente focado na relação produção-consumo" (HAN, 2018, p. 31). Nesse sentido, uma combinação sociotécnica permitiu uma nova individuação: a passagem da "representação" à "apresentação".

Antes da era das redes digitais, os utilizadores só podiam esperar a representação das suas identidades e culturas pelos atores tradicionais. Na era das redes digitais e do conteúdo autoproduzido, os utilizadores podem transmitir, controlar e negociar como gostariam que as suas identidades e culturas fossem percebidas como "apresentações" intencionais de si (ABIDIN, 2018, p. 10).

Netto e Barbosa (2019) advogam que as empresas usam o YouTube junto de crianças e jovens para influenciar familiares. Os produtores "dirigem-se à sua audiência para promover as marcas", agregando "personalidades" e "áreas de interesse", projetando "imagens estabelecidas" (RAMOS, 2018, p. 62-63). Assim nascem as "celebrity endorsement": união entre marca ou produto e sujeito humano (ELBERSE; VERLEUM, 2012). O fascínio do consumidor por aquele que é célebre tende a criar hábitos semelhantes nos seus seguidores - consumo, estilo, tendência (THOMSON, 2006).

Por seu turno, o influenciador digital é também um narrador (em inglês, um "storyteller"). A narrativa digital é a arte de combinar narrativas com mídias digitais, criando histórias curtas (ROBIN, 2008). Para Lambert (2006), são sete os elementos para histórias digitais eficazes: apresentar um ponto de vista, colocar uma pergunta dramática, oferecer conteúdo emocional, utilizar a voz para dar sentido às imagens, utilizar banda sonora apropriada, conciliar áudio e vídeo e, finalmente, gerir ritmos da história. Nesse aspecto, os casos abaixo analisados são exímios.

Todas essas dinâmicas vieram alterar a referência arquetípica do herói. Os clássicos (deuses ou heróis de contos de fadas) têm perdido terreno para os heróis de YouTube. Herói comum, muitas vezes ainda aluno, é capaz de contar piadas ou construir narrativas que emocionam e divertem os millennials, inscrevendo-se "numa nova 'ordem cósmica' que imana do poder da internet" (DIAS, 2019, p. 133). Esse culto nota-se pelas estatísticas: 76,4\% das crianças portuguesas (dos 9 aos 13 anos) acompanham youtubers. "36,4\% dedicam 1 hora, 18,2\% gastam 2 horas; 12,7\% ocupam 3 horas e 16,4\% dispensam 4 horas semanais a ver youtubers/canais" (ibidem, p. 136). As principais razões para seguir youtubers são: i) capacidade de domínio técnico; ii) capacidade de produzir conteúdos; iii) capacidade de entretenimento; iv) aspetos da personalidade; v) capacidade comunicacional; vi) projeção social. Já as razões que levam as crianças a querer ser youtubers são quatro: afirmação social, autorrealização pelo domínio técnico, autorrealização pelo teor dos conteúdos e valorização da plataforma YouTube (ibidem, p. 138). 


\section{Youtubers e arquétipos: metodologia e conceitos}

Comparar Brasil e Portugal, no que concerne à internet, implica dois pressupostos: os públicos dominam o mesmo idioma e as taxas de penetração da internet são diferentes (PONTE; BATISTA, 2019; TIC KIDS ONLINE BRASIL, 2018, 2019). Contudo, ao estudarmos youtubers focados em públicos infantojuvenis portugueses e brasileiros, pretendemos comparar e perceber se existem estratégias semelhantes, tentando perceber as relações efetuadas com os arquétipos bem como o modo como esses são utilizados.

Assim, no YouTube organizamos os vídeos do mais para o menos visualizado, inserimos as palavras correspondentes ao arquétipo em análise e escolhemos o mais visualizado dos três youtubers com a palavra-arquétipo correspondente. Finalmente, selecionamos apenas youtubers do top10 do ranking de visualizações, fornecido pela plataforma SocialBlade nos seus países de origem.

Justificamos essas escolhas por três ordens de razões: i) Brasil e Portugal são, no "espaço lusófono", os dois países com maior rácio entre visualizações e população (ver tabela 1); ii) a taxa de penetração da internet nos países lusófonos encontra nesses dois países maior semelhança (DIGITAL IN, 2017); iii) a utilização de dois países permite comparar qualitativamente, ajudando a perceber se as estratégias são comuns ou se diferem em função de algumas dinâmicas linguísticas ou culturais próprias.

\begin{tabular}{|c|c|c|c|c|c|}
\hline País & Nome do canal & Categoria & $\begin{array}{c}\text { Assunto } \\
\text { principal }\end{array}$ & $\begin{array}{c}\text { Rácio } \\
\text { visualizações/ } \\
\text { população }\end{array}$ & Visualizações \\
\hline Brasil & Felipe Neto & Entretenimento & $\begin{array}{c}\text { Quotidiano e } \\
\text { filosofia juvenil }\end{array}$ & $\mathbf{3 1 , 7 6 *}$ & 6.722 .434 .340 \\
\hline Brasil & Luccas Neto & $\begin{array}{c}\text { Produção e } \\
\text { divulgação }\end{array}$ & $\begin{array}{c}\text { Canal Infanto- } \\
\text { juvenil }\end{array}$ & $\mathbf{2 9 , 2 4 *}$ & 6.188 .468 .546 \\
\hline Portugal & Wuant & Entretenimento & $\begin{array}{c}\text { Quotidiano e } \\
\text { filosofia juvenil }\end{array}$ & $\mathbf{9 0 , 0 6 *}$ & 926.841 .616 \\
\hline
\end{tabular}

Tab. 1. Youtubers no TOP 10 por país analisado (Brasil e Portugal). Fonte: compilação própria a partir do SocialBlade. *Quociente entre visualizações e população por país (PORDATA, 2019; WORLD POPULATION REVIEW).

Os três youtubers no top 10, entre 01 e 15 de maio de 2019, eram Felipe Neto (Brasil), Luccas Neto (Brasil) e Wuant (Portugal).

O maior youtuber lusófono em visualizações é Felipe Neto. Inserido na categoria de "Entertainment", tem mais de 6,7 bilhões de visualizações e mais de 32 milhões de subscritores (ver figura 1). 


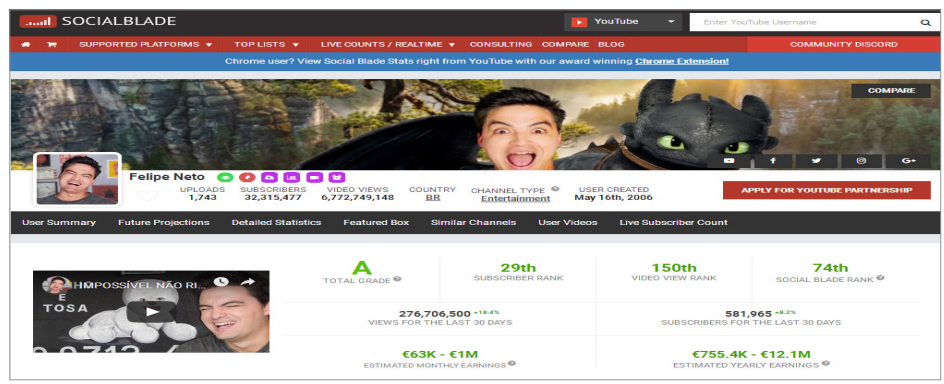

Fig. 1. Classificação e estatísticas de Felipe Neto no Social Blade. Fonte: https://socialblade.com/youtube/user/felipeneto.

O seu grande rival é precisamente o seu irmão, Luccas Neto. Conta com 6,1 bilhões de visualizações e com mais de 24 milhões de subscritores².

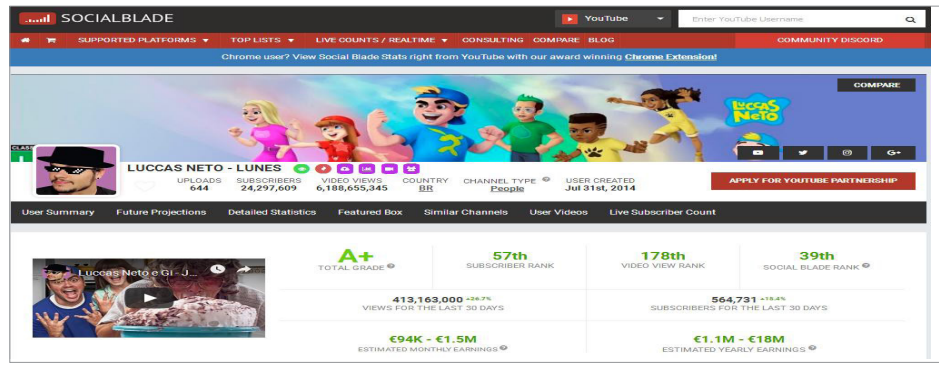

Fig. 2. Classificação de Luccas Neto no SBR. Fonte: https://socialblade.com/youtube/user/luccasneto.

Até a data deste estudo, nenhum outro youtuber se aproximou dos números dos irmãos. Contudo, Wuant, o maior youtuber português e único youtuber no top10 de Portugal, conta com uma vantagem: o seu rácio (visualizações/população do IP do país) é largamente superior a ambos (90,06 contra 31,76 de Felipe Neto e 29,24 de Luccas Neto). Isso configura uma taxa de penetração assombrosa (Tabela 1).

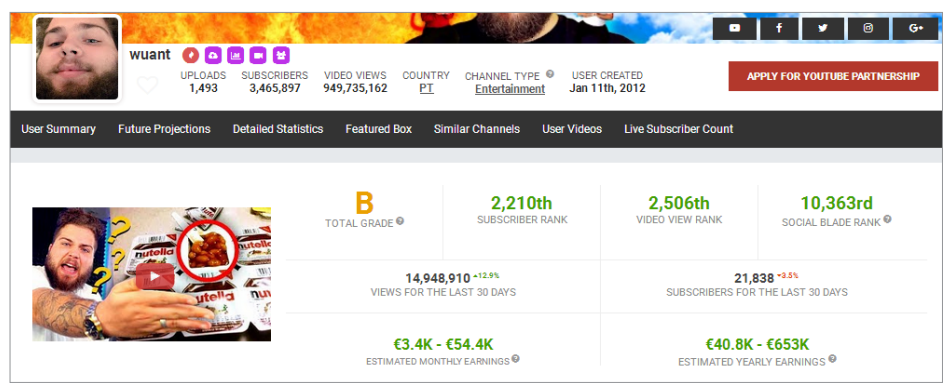

Fig. 3. Classificação de Wuant no SBR. Fonte: https://socialblade.com/youtube/user/imwuant.

2 Dados recolhidos no dia 09 de maio de 2019. 
Feita esta seleção, fomos à procura dos seus vídeos com mais visualizações, tendo no título uma das palavras que mencionam os arquétipos que vamos utilizar: anima, Sombra, Eu Superior, Criança, Mãe e Deus. Justificamos tal seleção devido à teoria dos arquétipos em Jung (RIBEIRO; BRUMLIK, 2007, p. 66-83).

Ao encontrarmos vídeos com a associação entre palavra e arquétipo nos títulos, condicionamos os vídeos e os assuntos, partindo do pressuposto de que o título está associado ao arquétipo. Escolhemos apenas o mais visto em cada caso.

Relativamente à teoria dos arquétipos, importa mencionar que estes "atuam enquanto reguladores e indutores da atividade criadora da fantasia, suscitando as configurações respectivas no patamar da consciência" (JUNG, 2011, p. 59). O modo como aparecem é o modo como espelham a sua contingência. A persona utilizada pelo youtuber, que narra uma história, funciona como um "recorte da psique coletiva". Essa "máscara que aparenta uma individualidade não passa de um papel ou desempenho através do qual fala a psique coletiva" (idem, 1979, p. 134).

Os principais arquétipos em Jung são seis: anima, Sombra, Eu Superior, Criança, Mãe e Deus (RIBEIRO; BRUMLIK, 2007). A "anima revela-se, enquanto representação do feminino no inconsciente masculino e o animus enquanto representação do masculino no inconsciente feminino" (ibidem, p. 67). Já a Sombra aparece como o destaque "intencional de partes separadas da própria personalidade apontadas como absurdas e imorais" (ibidem, p. 74). O Eu Superior "pode surgir tanto sob a imagem de fragilidade e debilidade extremas quanto sob a figura de personagens redentoras ou auxiliadoras" (ibidem, p. 75). O arquétipo de Criança aparece como o crescimento, a criação da autonomia, a passagem da criança pequena e frágil desde a origem, normalmente abandonada, até o triunfo sobre os opressores. O símbolo da Criança "fascina e cativa a consciência", permitindo um estado nascente libertador em direção a um futuro "triunfante" (JUNG, 2011, p. 171). O arquétipo de Mãe "é o fundamento do complexo de Mãe, que age diversamente sobre filhos e filhas, com autoridade, autonomia e elevação" (RIBEIRO; BRUMLIK, 2007, p. 80-81). Finalmente, o arquétipo de Deus confunde-se invariavelmente com os restantes. No entender da teoria dos arquétipos, constituíram-se apenas ramificações do mesmo, que seria a totalidade do inconsciente. No entanto, o Eu Superior seria aquele com maior aproximação. Em Jung (2011), há a convicção de que o Eu Superior é um Deus para o homem e que o arquétipo de Deus se revela como uma projeção do Eu Superior.

\section{Análise de casos}

A análise de casos serve para revelar o modo como aparecem os arquétipos e como estes se interligam na sua dinâmica sociotécnica e de storytelling. Assim, em alguns casos revela-se mais do que um arquétipo em cada um dos vídeos selecionados. 


\section{Anima e Sombra: unidos para o sucesso}

Começamos a análise com o arquétipo de anima. Para tal, consideramos o seu equivalente lógico: "mulher". Tal indicia uma associação entre o termo e o arquétipo, já que constitui a representação do feminino.

Encontramos em Felipe Neto o vídeo com maior número de visualizações (3,6 milhões) 3 , "Mexeram Com a Mulher Errada! Sensacional!!". Felipe Neto começa o vídeo com a expressão "hoje vamos falar de um vídeo sério, polêmico e que vai conter rebuliço". Apresenta dados: $37 \%$ da população concorda com a frase "mulheres que se dão ao respeito não são estupradas". Com um ar surpreso, argumenta com o objetivo de provar que "a roupa" e a "forma de vestir" nada têm a ver com assédio e com violação. Para isso, mostra um vídeo amador, de uma câmara oculta, em que uma mulher de vestido até os pés é "apalpada" por um homem, respondendo depois com uma agressão. Com isso insiste em provar que a roupa nada tem a ver com assédio. Repete com frequência o momento em que o homem apalpa a nádega da mulher e como ela reage - com um violento soco. Sublinha a resposta com o som "Pum" sobre esse instante violento. Felipe Neto defende e subscreve a força da anima, defendendo as mulheres em geral. Culpabiliza os homens que perpetuam esse tipo de violência.

No mesmo vídeo, Felipe Neto passa para um segundo exemplo. Em letras garrafais, começa com a frase "uma mulher vítima de assédio sexual agrediu o agressor". As letras estão a branco, exceto as palavras "agrediu o agressor", que estão a vermelho. O youtuber realça o argumento (não é a roupa que define o motivo do assédio) tendo como resposta vídeos que se resolvem com violência. O vídeo desenrola-se com a sequência homemapalpa-mulher; mulher-responde-com-murros.

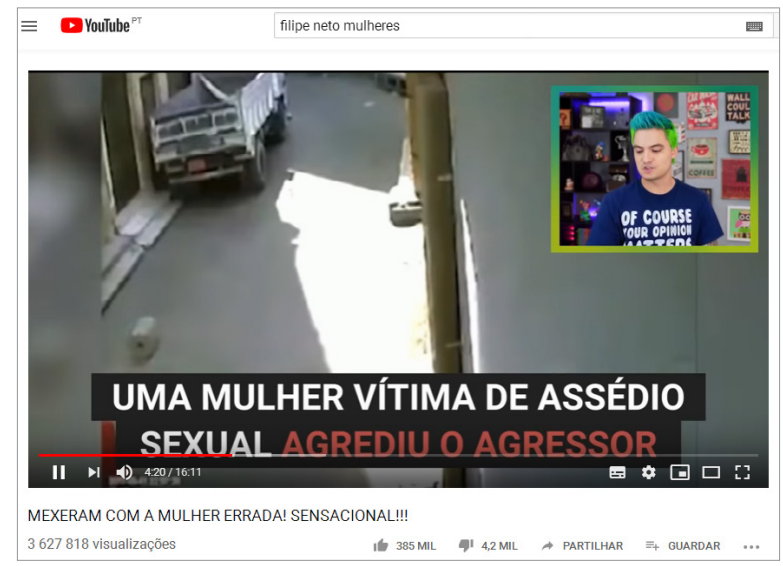

Fig. 4. Destaque para a ideia de "agressão". Fonte: https://www.youtube.com/watch?v=ZQJfuubgjbg

3 Vídeo consultado em https://www.youtube.com/watch?v=ZQJfuubgjbg\&t=376s, a 16/05/2019. 
No final dessa sequência, o youtuber justifica que não vem para o seu canal apelar para a violência, ainda que o tenha feito. $E$, na frase em que diz não apelar para a agressão sobre o agressor, descreve a satisfação da "vingança" obtida pelas agredidas.

Ao apelar para mulheres não reagirem com violência depois de a expor, Felipe Neto expõe um segundo arquétipo: a Sombra. Ou seja, incita os visualizadores a um reflexo, a um espelho. Sugere a moral de vingança, uma resposta "sombria" como modo de resolução. Lança dilemas. A Sombra aparece aqui a beneficiar o espetáculo, a sublinhar o lado "sensacional" (palavra essa escrita no título) do vídeo. O sensacional é o apalparviolentar e a sua reação violenta, mas também o facto de Felipe Neto expor o tema dessa forma, sujeitando o público ao lado sombrio e à violência.

Neste vídeo é exposto ainda um terceiro caso. A partir de uma câmara de um elevador, expõe uma situação em que um homem tenta se aproveitar do facto de estar isolado com uma mulher. Este aproxima-se e, ao colocar a mão no ombro da mulher, ela reage com uma palmada na mão do homem, seguida de um soco, um pontapé e uma joelhada.

No final da apresentação do caso, Felipe Neto sintetiza o seu argumento começando por referir que "esses casos provam que a aparência da mulher não tem a ver com assédio sexual". O youtuber reforça que a violência que o homem faz à mulher, à anima, não depende do facto de a mulher ter roupa mais ou menos atrevida. Porém, o que Felipe Neto acaba por sugerir indiretamente é a dicotomia "agredir versus responder-com-agressão". A relação efetuada entre anima e Sombra beneficia a contingência ecrãnica: o sensacional e o violento, sublinhados por uma moral que vai de encontro à defesa do feminino. Existem vertentes comerciais e sensacionalistas no processo. Não uma propaganda empresarial, mas um tipo de inteligência social: expor violência e ficar de acordo com um intelecto contingente comum, como é o caso dos direitos fundamentais (SHERERWARREN, 2006). Ou seja: a resposta da anima aos excessos masculinos gera a base para a criação de conteúdos de acordo com as forças da época. Por seu turno, a Sombra aparece como matriz de um mundo que, mais do que justiça, clama por violência, obtendo lucros por meio do grande número de visualizações (HIKIJI, 2012).

\section{Eu Superior e Criança em Luccas Neto}

Para analisarmos o arquétipo de "Eu Superior", utilizamos a palavra "personagens". Partimos do pressuposto de que o conceito de Eu Superior está associado a figuras e heróis infantis e juvenis, e isso gera associação entre o herói (Eu Superior) e a criança ou jovem. Assim, o vídeo com mais visualizações que encontramos foi o de Luccas Neto: "Desafio colorindo aprendendo as cores" (8 milhões de visualizações) ${ }^{4}$.

Focado no público infantil, Luccas anuncia o desafio: usar três cores para pintar e desenhar heróis. Vestido de modo colorido e com boné para trás, apresenta-se sobre um fundo azul e com bisnagas de tinta de várias cores, reforçando a expressão "no meu canal tudo vira diversão". Diz o que vai fazer e, a cantar, sorridente, apela para

4 Pode ser visto em https://www.youtube.com/watch?v=eR-jDqdyE7Y. 
a inscrição no seu canal. No final da cantiga, de braços abertos, acaba por atirar algumas bisnagas ao chão (como se fosse sem querer).

Começa por escolher um desenho de uma figura infantil: Olaf, do filme Frozen. O objetivo é pintar a silhueta com três cores resultantes de uma escolha cega. O vídeo desenvolve-se com o youtuber a fazer pequenas asneiras: pinta mal o desenho; pinta "sem querer" a mesa; limpa a mesa e suja a mão; coloca a mão suja na cara, sujandose ainda mais. Ou seja, Luccas revela o "Eu Superior" como sendo o de uma criança frágil e meiga, com debilidades extremas a pintar, cheia de imperfeições. No final dessa primeira sequência, apela para as crianças fazerem isto em casa: brincar, pintando, ainda que nada corra bem. O importante, diz, é a diversão.

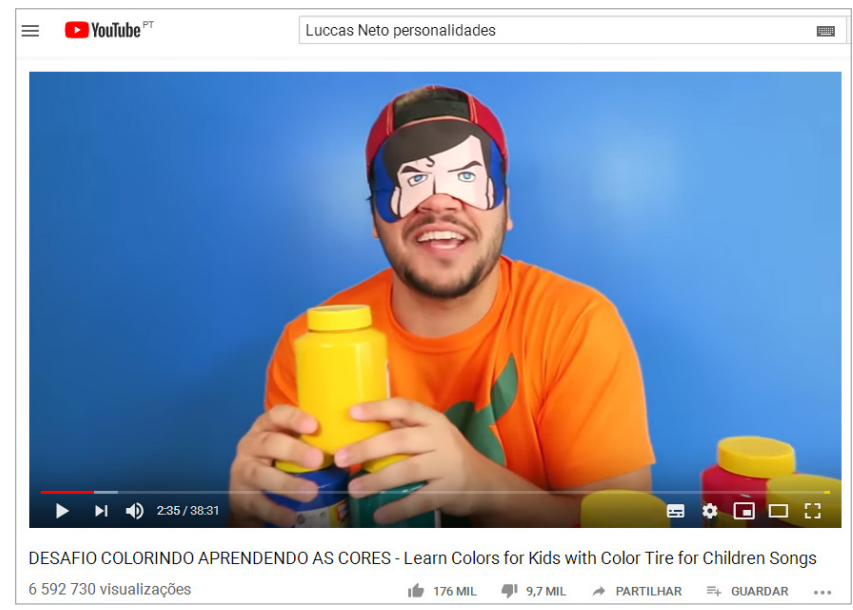

Fig. 5. Luccas Neto expondo a criança superior. Fonte: https://www.youtube.com/watch?v=eR-jDqdyE7Y

A partir do minuto 12, muda a brincadeira temporariamente apenas para apelar para a compra do livro de coleção de Tazos com a sua marca. Depois, regressa a um novo desenho para pintar: o herói Ben Tem. Faz o mesmo jogo: escolhe cores de olhos vendados para pintar. Desta feita, pinta melhor. No final, ao tentar imitar com gestos o poder de transformação desse herói para "combater os opressores", volta a fazer asneira com as tintas. Mas, como um herói, remedeia a situação apelando ao triunfo. O triunfo é, neste caso, a diversão.

Na terceira sequência, a figura é a Mônica de "A Turma da Mônica". Faz o mesmo: escolhe cores e faz brincadeiras. Conclui com sucesso a pintura, mas acaba com "besteirinha", revelando novamente o "seu" lado imperfeito ainda que "libertador e divertido".

A narrativa neste vídeo implica a presença de um "Eu Superior" que se revela frágil, imperfeito e fazedor de asneira, regado por um arquétipo de criança, libertador e divertido, que triunfa pelo poder de aceder ao mundo do consumo e das vendas. Foi nesse sentido 
que Maria Monteiro (2018) o descreveu em "Entretenimento e incentivo ao consumismo no canal do youtuber Luccas Neto". A autora concluiu que o consumismo produzido por esse youtuber resulta de um "conjunto de processos socioculturais em que se realizam a apropriação e os usos de produtos" e que lhe somam a subjetividade e os processos comunicacionais (CANCLINI, 199, p. 77). Nesse canal, Luccas Neto é um "homem adulto que se infantiliza para conseguir inscritos com o público infantil e contatos com marcas" (MONTEIRO, 2018, p. 5). Além disso, nos títulos desses vídeos, os adjetivos "maior", "gigante" e "monstruoso", bem como quantidades consideráveis expressas em números, se associam a marcas e produtos (MONTEIRO, 2018, p. 8-9). Essas estratégias de "caça-clique" espalham-se, de modo segmentado, por nove tipologias: compras, teatros, unboxing, brincadeira, desafio, resenha, coleção, Tour e tutorial. Tais estratégias permitem a fusão entre os arquétipos "Criança" e "Eu Superior", alimentando a persona aqui descrita. Há toda uma ciência da promoção por detrás de uma aparência inócua. Como sugere Monteiro (2018, p. 9-11), "quando vê o youtuber que admira mostrando produtos em seus vídeos, como Nutella e armas de brinquedo Nerf, a criança tende a acreditar na opinião dele e pode ser persuadida a desejar a mesma mercadoria". Não é por acaso que também a imagem promocional de Wuant, presente na figura 4, tem o youtuber a apontar para o produto Nutella. Eis uma estratégica imitação tribal entre youtubers.

\section{O arquétipo Mãe e a fusão com estereótipos}

Para estudarmos a presença do arquétipo de Mãe num dos youtubers em análise, voltamos ao mesmo procedimento: utilizamos a palavra "mãe" na busca. O mais visualizado é o vídeo de Wuant, com mais de 1 milhão de visualizações: "Coisas de Mãe"

Nesse vídeo, Wuant descreve a centralidade da mãe na sua vida. O vídeo desenvolvese a discorrer sobre os "poderes da mãe" em situações diferentes: o poder do "beijo da mãe"; o poder da Mãe para organizar e arrumar o mundo (sobretudo o doméstico); a velocidade da Mãe a fazer qualquer coisa que se peça; e, finalmente, o poder da Mãe em querer tudo limpo. O youtuber narra sobre o sentido de limpeza e pureza das "Mães", a garantia de que, com elas, para além de curado de beijos (cura emocional), organizado e veloz, o mundo se garante limpo e higiénico.

Aqui, a presença da "Mãe" é central. Evoca o arquétipo, mas junta-Ihe o estereótipo: a mãe como dona-de-casa. Embora tenha revelado os seus "poderes", apenas a revela com autoridade como cuidadora, organizadora, arrumadora. Mais do que um arquétipo, revela um estereótipo.

O arquétipo "Mãe" é então apresentado como um estereótipo, reforçando os "super-poderes" de persistência, consistência ou organização de ideias e coisas, focando apenas a dimensão doméstica e cuidadora. O que, em certo sentido, nos coloca a pensar no confronto entre o "ator-na-rede" e o modo como se renovam os arquétipos.

5 Pode ser visto em https://www.youtube.com/watch?v=-x30FPUTkZ8. 
Uma inquietação teórica: não estarão os arquétipos constantemente sujeitos à dinâmica contingente dos estereótipos e das representações sociais, bem como das suas associações na rede de coisas humanas e não humanas? Estamos diante do arquétipo herdado ou do arquétipo misturado com o contingente?

\section{Deus entre os Youtubers}

Ao escrevermos a palavra "Deus", o vídeo com mais visualizações é "Felipe Neto é Deus? Que é que é isso?". Nesse vídeo, Felipe dá conta de um outro youtuber com o vídeo "Nunca fale mal de Felipe Neto. Ele é um Deus!". O vídeo desenvolve-se em torno desse. Esse outro youtuber efetua uma defesa de Felipe Neto, tendo como estratégia colocar no crítico o desafio de fazer melhor. Isso é, "o outro", que não gosta do que eu gosto, é visto como uma espécie de inimigo (HAN, 2018).

Então, Felipe Neto começa por tentar educar esse youtuber de modo a dar-lhe outros argumentos de defesa, anulando os utilizados. Felipe sugere-se como uma espécie de Eu Superior sobre o fã, educando-o, instruindo-o e considerando-se um herói entre os que o defendem. Felipe Neto coloca-se no lugar de um Deus, redentor e auxiliador.

\section{Considerações finais}

A análise de arquétipos nesses youtubers revela parte do seu sucesso. O modo como esses são convocados, juntamente com as estratégias utilizadas no storytelling e as dinâmicas de marketing, casam perfeitamente quando orientados para grandes massas de públicos infantojuvenis. A ligação entre arquétipos, ora de modo estratégico, ora de modo prático e pragmático, como por exemplo na fusão entre anima e Sombra ou entre Eu Superior e Criança, revela tanto uma inteligência social entre os que pensam os vídeos como uma inteligência prática que já funciona noutros tipos de ecrãs (PEREIRA, 1998).

Nesse sentido, este estudo corrobora a ideia de que as escolhas dos conteúdos são fruto de estratégia e manipulação. Mesmo entre os que não consomem esses produtos, a força de influência transfere-se para os influenciados, uma vez que, como sugeria Tarde (1978), as suas apreensões circulam e transformam-se em intersubjetividades. $\mathrm{O}$ "romano" não consegue escapar a essa influência. Daí os importantes alertas para a educação no consumo da internet.

Percebe-se também que esses youtubers estão focados em resultados, não apenas para beneficiarem os respectivos canais como também os produtos que promovem. O capital utilizado para legitimar o que querem afirmar, como foi o caso de Felipe Neto a tentar convencer para a ausência de sentido entre assédio e provocação, comporta objetivos de alcance do "espetáculo procurado pelas sociedades", como a violência, o conflito e a polarização (DÉBORD, 2012). Não interessa o porquê nem o como, mas antes a "prova" com base na imagem simbólica. Essa questão expõe a problemática 
relacional entre arquétipos e exploração comercial. Vimos, na análise da anima, a vingança face aos ataques violentos do masculino. No entanto, por necessidades numéricas de procura de resultados, percebeu-se uma clara apropriação do argumento e do arquétipo em direção ao sombrio que se encontra na violência, mas que comporta o espetáculo e o sensacional. Essa mesma lógica imperou ainda na estratégia de fundir o arquétipo de criança com o arquétipo de Eu Superior: sublinha-se a importância do devir libertador e infantil, mas subscreve-se a sua pertinência pela via de uma legitimação, tendo como base uma orientação do futuro-presente hedonista - a diversão acima de tudo. Os arquétipos, nos casos analisados, ficaram ao serviço de estratégias numéricas.

Com recurso a imagens, montagens e vídeos, percebe-se o youtuber como mais do que um "líder de opinião", que detém mais do que "influência pessoal". Estes constroem e alimentam estereótipos, sublinham estratégias e narrativas comerciais e alimentam públicos. Contudo, a maior influência talvez esteja ao serviço do próprio digital: captura da atenção, visualizações e partilhas.

Os casos analisados reforçam a investigação de Monteiro (2018), no sentido de que há qualquer coisa nestes que se infantiliza para conseguir resultados. Mas importa questionar: não é também de infantilização que é feita a estratégia na política e nos tradicionais massmedia? Não é este o seu eco e seu resultado? Tal como muitas vezes acontece noutros meios (cinema e televisão), há um uso de arquétipos, muitas vezes não consciente ou negligenciado, que transporta, socializa e dispõe para a imitação e adaptação. As personas destes youtubers refletem e propagam um intelecto contingente circulante, colocando arquétipos comuns ao seu serviço: consumo, produção, ideias, opiniões, estereótipos.

Notamos ainda a "expulsão do outro", referida por Han (2018), quando estudamos a presença do arquétipo de Deus em Felipe Neto. A legitimação de um "eu" em detrimento de um "outro" tendo como motivo o ego e o numérico. Essa "expulsão do outro" gera um mundo de idênticos: consomem, pensam e visualizam o mesmo. Esse centralismo no eu, eliminando o outro, advém também da ideia do ser "autor e criador de si mesmo", uma "receita" da publicidade global, uma "autenticidade sobretudo através do consumo" (HAN, 2018, p. 9). Os youtubers são também o reflexo dessas forças.

Em suma, o império do numérico está na base da "passagem de uma organização para outra mais complexa e diferenciada, acompanhada de outro padrão de individuação" (ELIAS, 1993, p. 189). E que padrão é esse? Toda uma rede de associações entre arquétipos e imagens e vídeos que serve de substrato para orientar o ator na sua contingência sociotécnica. OYouTube é um actante nesse padrão de individuação, e tal necessita de ser continuamente conhecido, aprofundado e ensinado sob pena de servir de modo acrítico entre as camadas mais jovens. 
Pedro Rodrigues Costa é doutor em Ciências da Comunicação (Sociologia da Comunicação e Informação), pela Universidade do Minho. Entre suas áreas de investigação constam as questões em torno da Cibercultura, Tecnologia e Estudos sobre redes sociais digitais. É investigador do CECS, onde integra o Grupo de Estudos Culturais e o Museu Virtual da Lusofonia. Destacam-se, nas suas diversas competências de investigação, a análise de dados em SPSS e a análise de conteúdo em NVIVO.

pcosta7780@gmail.com

\section{Referências}

ABIDIN, C. Internet celebrity: understanding fame online. United Kingdom, North America, Japan, India, Malaysia and China: Emerald Publishing, 2018.

ARISTÓTELES. Metafísica. São Paulo. Edições Loyola, 2012.

BURGESS, J.; GREEN, J. YouTube e a revolução digital: como o maior fenômeno da cultura participativa está transformando a mídia e a sociedade. São Paulo: Aleph, 2009.

DIAS, E. R. F. A visão do sagrado pelos millennials: a idolatria dos youtubers. Journal of the Sociology and Theory of Religion (S.1), v. 8, p. 131-145, 2019.

ELBERSE, A.; VERLEUN, J. The economic value of celebrity endorsements. Journal of Advertising Research. v. 52, n. 2, p. 149-165, 2012.

ELIAS, N. O Processo Civilizador: formação do estado e civilização. Rio de Janeiro: Zahar, 1993.

FELINTO, E. Videotrash: o YouTube e a cultura do "spoof" na internet. Revista Galáxia, v. 16, p. 33-42. São Paulo, 2008.

FOUCAULT, M. Microfísica do poder. Rio de Janeiro: Graal, 2000.

HAN, B. C. A expulsão do outro: Sociedade percepção e comunicação hoje. Lisboa: Relógio D'Água, 2018.

HIKIII, R. Imagem-violência. Etnografia de um cinema provocador. São Paulo: Terceiro Nome, 2012.

JUNG, C. Os Arquétipos e o Inconsciente Coletivo, Lisboa: Editora Vozes, 2011.

JUNG, C. O Eu e o Inconsciente. Petrópolis: Editora Vozes, 1979.

LAMBERT, J. Digital storytelling: Capturing lives, creating community. Berkeley, CA: Digital Diner Press, 2006.

LATOUR, B. Reagregando o social: Uma introdução à Teoria do Ator-Rede. Salvador: Edufba, 2012.

MCLUHAN, M. Os meios de comunicação como extensões do homem. São Paulo: Cultrix, 2007.

MARTINO, L. Lendo "The People's Choice" no seu $70^{\circ}$ aniversário: do "líder de opinião" aos "influenciadores digitais". Intercom. v. 41, n. 3, p. 21-32. São Paulo, 2018.

MENEZES, G. B. Usos e Gratificações: uma revisita à Teoria que deu um novo impulso aos estudos de receção. In: SOUZA, R.; MELO, J.; MORAIS, O., Teorias de Comunicação: correntes de pensamento e metodologia de ensino. São Paulo: Intercom, v. 14. p. 551-558, 2014. 
MESSA, E. Influenciadores Digitais? \#WTF: uma reflexão sobre a falta de visão das agências de publicidade sobre o universo de influência online. Youpix, 2016.

MONTEIRO, M. Entretenimento e incentivo ao consumismo no canal do YouTuber Luccas Neto. In: Anais do $\mathbf{4 1}^{\circ}$ Congresso Brasileiro de Ciências da Comunicação. Joinville: Intercom, 2018.

NETTO, A.; BARBOSA, I. A influência da criança no poder de compra de uma família: o quão importante é a educação familiar no consumo. Race, v. 3, 2019.

PALACCE, M. A mulher na propaganda: um olhar sobre os arquétipos femininos nas produções publicitárias. Publicidade no Plural. Análise e Reflexões. Ebook. p. 34-43. São Paulo: Universidade metodista, 2011

PEREIRA, S. A televisão na família: processos de mediação com crianças em idade pré-escolar. IEC: Universidade do Minho, 1998.

PONTE, C.; BATISTA, S. EU Kids Online Portugal. Usos, competências, riscos e mediações da internet reportados por crianças e jovens (9-17 anos). EU Kids Online e NOVA FCSH, 2019.

RAMOS, J. Comunicação e influenciadores digitais: Contributos para o estudo dos estilos de vida alimentares e desportivos. Lisboa: ISCSP, 2018.

ROBIN, B. Digital storytelling: A powerful technology tool for the 21 st century classroom. Theory Into Practice, v. 47, n. 3, p. 220-228, 2008.

SERRANO, P. Cognição e interacionalidade através do YouTube. Revista Galáxia, São Paulo, v. 16, p. 33-42, 2008.

SHERER-WARREN. Das mobilizações às redes de movimentos sociais. Sociedade e Estado. Brasília, v. 21, n. 1, p. 109-130, 2006.

TARDE, G. A Opinião e as Massas. São Paulo: Martins Fontes, 1992.

TARDE, G. As Leis da Imitação. Porto: Rés Editora, 1978.

THOMSON, M. Human brands: Investigating antecedents to consumers' strong attachment to brands. Journal of Marketing, v. 70, n. 3, p. 104-119, 2006.

TIC kids online Brasil 2018. Pesquisa sobre o uso da internet por crianças e adolescentes no Brasil. Núcleo de Informação e Coordenação do Ponto BR: São Paulo, 2019.

TOFFLER, A. A Terceira Vaga. São Paulo: Editora Livros do Brasil, 1999.

VIRILIO, P. A Velocidade de Libertação. Lisboa: Relógio D'Água, 2001.

Artigo recebido em 19/02/2020

e aprovado em 05/04/2020. 